\title{
Frequency Regulation and Coordinated Control for Complex Wind Power Systems
}

\author{
Cheng Guo ${ }^{1}{ }^{1}$ and Delin Wang ${ }^{2}$ \\ ${ }^{1}$ Yunnan Electrical Power Experiment Institute, Co., Kunming 650217, Yunnan, China \\ ${ }^{2}$ School of Electric Engineering, Southwest Jiaotong University, Chengdu 610031, Sichuan, China \\ Correspondence should be addressed to Cheng Guo; gc325@126.com
}

Received 25 February 2019; Accepted 17 April 2019; Published 16 May 2019

Guest Editor: Chun Wei

Copyright (c) 2019 Cheng Guo and Delin Wang. This is an open access article distributed under the Creative Commons Attribution License, which permits unrestricted use, distribution, and reproduction in any medium, provided the original work is properly cited.

\begin{abstract}
With the development of complex renewable energy systems, the frequency control and regulation of the power grid powered by such renewable energies (e.g., wind turbine) are more critical, since the adopted different power generators can lead to frequency variations. To address the frequency regulation of such power grids, we will present a variable coefficient coordinated primary frequency regulation scheme for synchronous generator (SG) and doubly fed induction generator (DFIG). The variable adjustment coefficient of DFIG is defined according to the current reserve capacity, which can be applied to adjust different operation conditions to regulate the frequency variation within a predefined allowable range. Since the DFIG can make full use of the reserve wind power in the system frequency regulation, the proposed method can address both the frequency regulation response and the economic performance. Simulation results indicate that the proposed coordinated control scheme can achieve satisfactory frequency regulation response and lead to reduced demand for frequency regulation of SG.
\end{abstract}

\section{Introduction}

The wind power industry in all countries of the world is developing at a relatively fast speed. By $2050,100 \%$ renewable energy can be supplied to the world, of which wind power accounts for $40 \%[1,2]$. This indicates that wind energy will gradually become the main source of renewable energy in the future. Today, wind power technology is relatively mature; however, wind power has a highly uncertain nature because wind speed is greatly affected by environmental conditions such as temperature and airflow changes. The connection of more wind power to power grid not only has many problems in the operation of the wind farm itself but also brings difficulties to the operation and regulation of the power grid $[3,4]$. The traditional doubly fed induction generator- (DFIG) based wind turbine does not have frequency regulation capability because its rotor speed is completely decoupled from the system frequency. Thus, the inertial response and frequency regulation capability of the power grid are influenced in this configuration. Nowadays, some wind power industries in developed countries have required that wind farms should have a certain frequency regulation capability by proposing advanced strategies. However, it is recognized that the adjustable frequency range of DIFG-based wind turbines is seriously limited by the wind speed [5]. Moreover, the wind power is usually included in the frequency regulation, making it a complicated process during the coordination with the traditional synchronous generators [6].

To address the above issues, many efforts have been done to investigate the feasibility to incorporate wind power into power grid frequency regulation in recent years by developing advanced control strategies and frequency regulation schemes [7, 8]. In [9-11], the potential problems caused by the large-scale wind power integration were introduced, and the recent research progress of two essential related aspects, control strategy and frequency regulation capability, has been reviewed. In terms of DFIG control designs, the authors of [12-15] proposed using proportional, differential controller (PD controller) to construct a primary frequency regulation controller on the rotor side, where the corresponding converter was designed, so that DFIG can adapt quickly to the frequency changes induced in the system. Moreover, 
after developing speed control schemes, the authors of [1618] proposed several composite frequency control schemes for variable speed wind turbines by combining the variable pitch control approaches and virtual inertial control methods. In [19], the variable droop is introduced to enhance the primary frequency contribution of wind turbine generators (WTG), and the droop parameter of every WTG is regulated to optimize the power output according to the reserve power margin available. In [20], a reduced-order modelbased integrated controller method was suggested, which can provide inertial response and primary frequency control for WTG. This controller allows for a coupled control of torque and pitch angle at all speed range of DFIGs. In [21], simulation results indicate that the inertial term can be omitted, and the synthetic inertia strategy reduces to a very fast droop control strategy. It is noted that all the above-mentioned methods have been proposed from either the perspective of the wind farms or the internal control synthesis of wind turbines to study the possibility and validity of using wind power in the frequency regulation of power grid. However, when the wind power with variable frequency is incorporated into the power grid as a new type of frequency regulation power supply, the economic performance of the DFIG-based wind turbines and the ability of system frequency regulation should be considered simultaneously. Therefore, in order to obtain better power grid response and frequency modulation ability, it is necessary to coordinate the frequency regulation outputs between the DFIGs and the synchronous generators, according to the adjustable frequency capacity of DFIG-based wind turbines under different wind speeds. In fact, this idea has been recognized as one of emerging research topics as it can improve the wind frequency regulation.

Inspired by the above discussion, this paper explores the feasibility of using DFIGs to implement frequency regulation from the point of view of the adjustment coefficient. We found that the adjustable frequency wind turbines can effectively undertake the frequency regulation responsibility of the power grid. We propose a coordinated primary frequency regulation strategy between the synchronous generators and the DFIG-based wind turbines by using the variable coefficients. The strategy considers the influence of wind speed variation upon DFIG's wind energy acquisition and improves the maximum power point tracking (MPPT) [22, 23] operation mode of traditional DFIG. In the MPPT region, DFIG achieves deloading operation by controlling the rotor speed to deviate from MPPT operating point; in the constant power region, DFIG operates in deloading operation by controlling the pitch angle so as to reserve active power for DFIG to participate in primary frequency regulation of power grid. This strategy takes into account the frequency regulation ability and economic performance. In the allowable range of frequency variations, the DFIG can make full use of spare capacity to participate in the system frequency regulation. It can not only reduce the frequency regulation pressure of the synchronous generators but also reduce the wind power curtailment indirectly. Finally, the simulation result demonstrates the effectiveness of the proposed strategy. The main contribution of this paper is to introduce a variable coefficient coordinated frequency regulation for SG and
DFIG, which can adapt to different operation conditions to make full use of the reserve wind power, and address both the frequency regulation response and the economic performance.

The structure of this paper is described as follows: Section 2 provides the system modeling and problem formulation. Section 3 presents the coordinated control scheme for generators. The coordinated frequency regulation strategy is given in Section 4, and numerical simulations are shown in Section 5. Finally, some conclusions are given in Section 6.

\section{System Formulation and Problem Statement}

In this paper, the studied system includes the synchronous generator (SG) and DFIG-based wind turbine generator (WTG). The connection structure between SG and WTG is shown in Figure 1(a). The WTG system for primary frequency regulation consists of aerodynamics model, pitch angle control system as shown in Figure 1(b), DFIG with supplementary controller to realize inertial response, and lookup tables to compute maximum and deloading power.

In Figure 1(b), $f$ is the current frequency, $f_{N}$ is the rated frequency, $\omega^{*}{ }_{r}$ is the expected angular velocity, $\omega_{r}$ is the current angular velocity, $\beta_{0}$ is the reserved pitch angle for load shedding, $K_{\beta}$ is the proportional coefficient, $T_{\beta}$ is the time constant of the controller, and $\beta_{\max }$ and $\beta_{\min }$ are the maximum and minimum limit of pitch angle. Compared with the traditional pitch angle control, the frequency response link of pitch angle is added, and the frequency deviation of power grid is used as input. By adjusting the pitch angle to respond to the frequency change, DFIG-based wind turbines can provide long-term power support for the power grid.

A simplified aerodynamic model is used when the electrical behavior of the wind turbine is the main interest of the study. The relationship between the wind speed and the aerodynamic torque can be described as

$$
T_{\mathrm{W}}=\frac{1}{2} \rho \pi R^{3} v^{2} C_{P}(\theta, \lambda)
$$

where $T_{\mathrm{w}}$ is the aerodynamic torque extracted from the wind, $\rho$ is the air density, $R$ is the wind turbine rotor radius, $v$ is the equivalent wind speed, $\theta$ is the pitch angle of the rotor, $\lambda$ is the tip speed ratio, and $C_{\mathrm{p}}$ is the aerodynamic efficiency of the rotor.

Numerical approximations have been developed to calculate $C_{\mathrm{p}}$ for given values of $\theta$ and $\lambda$. Here the following approximation is used as

$$
C_{P}(\theta, \lambda)=0.22\left(\frac{116}{\lambda_{i}}-0.4 \theta-5.0\right) e^{-12.5 / \lambda_{i}}
$$

where

$$
\lambda_{i}=\frac{1}{1 /(\lambda+0.08 \theta)-0.035 /\left(\theta^{3}+1\right)}
$$

Actually, the dynamic characteristics of DFIG and power grid are decoupled in conventional MPPT control method; the wind turbines cannot respond to the system frequency 


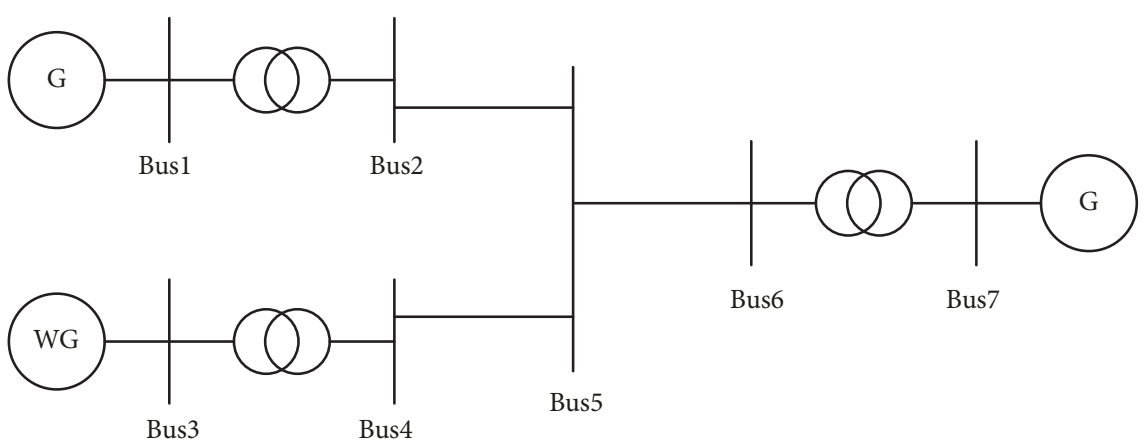

(a) Wiring diagram of WTG and SG

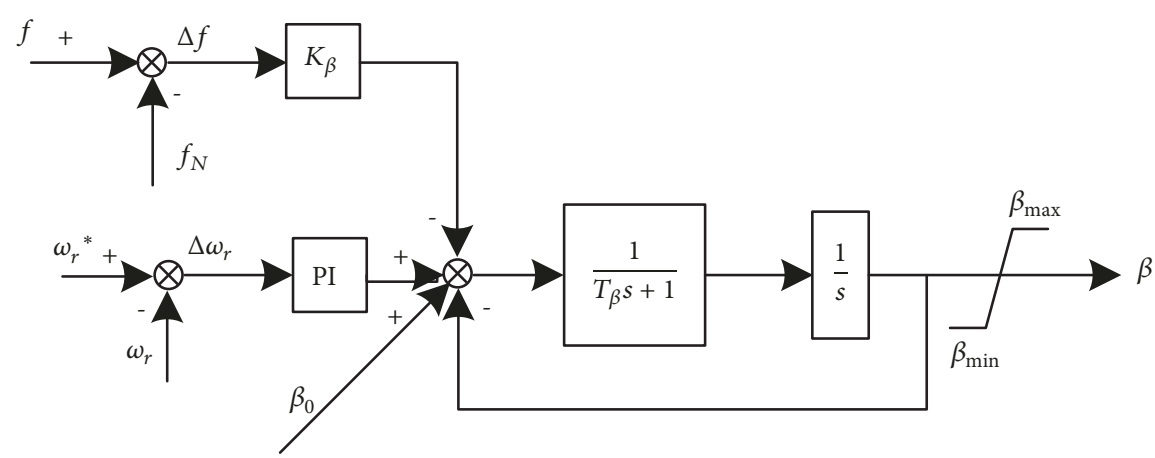

(b) Improved pitch angle control structure

FIGURE 1: Structure of power system including wind turbines and main controller.

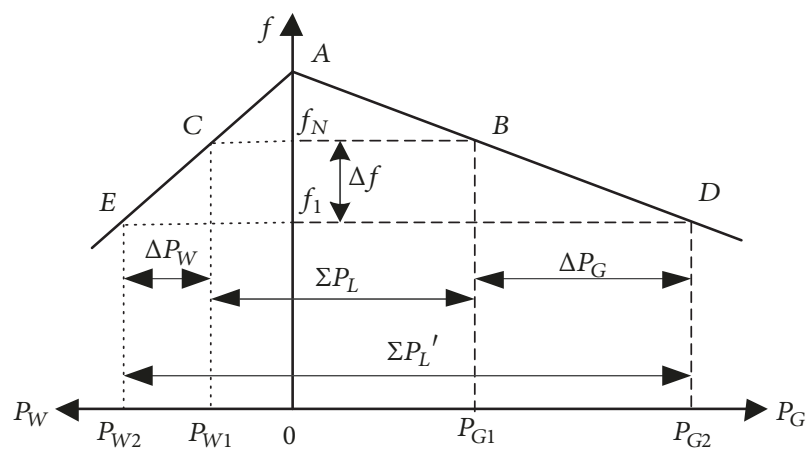

FIGURE 2: Frequency regulation characteristics of synchronous generator and DFIG-based wind turbine in parallel operation mode.

changes. However, the rotational inertia stored in WTG is remarkable; hence, there exists the waste of rotational inertia of DFIG rotor on the traditional operation mode. However, if there is an appropriate operation condition, it can be fully released and utilized through proper control strategy to support the system stability. The aim of this paper is to develop a new control strategy for WTG to participate in the primary frequency regulation, and the coordinated control strategy between SG and DFIG for primary frequency regulation is explored.

\section{Coordinated Control of Synchronous Generators and DFIG-Based Wind Turbines}

3.1. Frequency Regulation Characteristics. According to the primary frequency regulation principle of $S G$, the adjustment coefficient, namely, $R_{\mathrm{W}}$, of the DFIG-based wind turbine is defined as

$$
R_{\mathrm{W}}=-\frac{\Delta f}{\Delta P_{\mathrm{W}}}
$$

where $\Delta P_{\mathrm{W}}$ is the frequency regulation of DFIG and $\Delta f$ is the frequency variation of system.

When a synchronous generator and a DFIG-based wind turbine are connected in parallel, the relationship between the frequency regulation characteristic and the active power allocation among generators can be illustrated in Figure 2. In the figure, $\overline{A B D}$ represents the adjusting characteristic curve of the synchronous generator. $\overline{A C E}$ represents that of the DFIG-based wind turbine. We suppose that the total load of the system is $\Sigma P_{\mathrm{L}}$, which is corresponding to the line segment 
$\overline{C B}$ in the figure. When the system frequency is $f_{\mathrm{N}}$, the load carried by the synchronous generator is $P_{\mathrm{Gl}}$, and the load carried by the wind turbine is $P_{\mathrm{W} 1}$, such that

$$
P_{\mathrm{G} 1}+P_{\mathrm{W} 1}=\sum P_{\mathrm{L}}
$$

After the system load increases $\Delta P_{\mathrm{L}}$ and then is stable at $f_{1}$, the power output increase of the synchronous generator is $\Delta P_{\mathrm{G}}$ and the total generated power output is $P_{\mathrm{G} 2}$; the power output increase of the wind turbine is $\Delta P_{\mathrm{W}}$ and the total power output is $P_{\mathrm{W} 2}$. The sum of the increased power output of two generators is $\Delta P$. According to Figure 1 and (4), we can obtain

$$
\frac{\Delta P_{\mathrm{G} *}}{\Delta P_{\mathrm{W} *}}=\frac{R_{\mathrm{W} *}}{R_{\mathrm{G} *}}
$$

where $\Delta P_{\mathrm{G} *}$ and $\Delta P_{\mathrm{W} *}$ represent the per unit values of power output of the synchronous generator and DFIG-based wind turbine, respectively; $R_{\mathrm{G} *}$ and $R_{\mathrm{W} *}$ are the per unit values of adjustment coefficients of the synchronous generator and DFIG-based wind turbine, respectively.

According to (6), when a synchronous generator and a DFIG are operated in parallel mode and the power increments of generators are retained at their respective per unit values, the power allocation between the SG and DFIGbased wind turbine is inversely proportional to the respective adjustment coefficients. That is, the generator with smaller adjustment coefficient has larger load increment, while the generator with larger adjustment coefficient has smaller load increment. Thus, the following can be concluded: (1) when a synchronous generator and a DFIG-based wind turbine run in parallel, the DFIG-based wind turbine participating in the frequency regulation can effectively reduce the frequency regulation pressure of the synchronous generator; (2) the frequency regulation output of the synchronous generator and DFIG-based wind turbine can be coordinated by adjusting the ratio of $R_{\mathrm{G} *}$ to $R_{\mathrm{W} *}$.

3.2. Coordinated Control Strategy after DFIG-Based Wind Turbine Connected to the Power Grid. In the primary frequency regulation, the frequency regulation output of the synchronous generator is given by

$$
\Delta P=-\frac{1}{R_{*}} \frac{\Delta f}{f_{\mathrm{N}}} P_{\mathrm{N}}
$$

where $\Delta f$ is the system frequency deviation, $f_{\mathrm{N}}$ is the system rated frequency, $R_{*}$ is the per unit value of adjustment coefficient, and $P_{\mathrm{N}}$ is the rated capacity of the generator.

When a DFIG and $n$ synchronous generators are operated in parallel, according to (7), the adjustment equations are given as follows:

$$
\begin{aligned}
& \Delta P_{\mathrm{G} i}=-\frac{1}{R_{i *}} \frac{\Delta f}{f_{\mathrm{N}}} P_{\mathrm{GiN}} \quad(i=1,2, \ldots, n) \\
& \Delta P_{\mathrm{W}}=-\frac{1}{R_{\mathrm{W} *}} \frac{\Delta f}{f_{\mathrm{N}}} P_{\mathrm{WN}}
\end{aligned}
$$

where $\Delta P_{\mathrm{G} i}$ and $\Delta P_{\mathrm{W}}$ are the frequency regulation outputs of synchronous generator $i$ and DFIG-based wind turbine, respectively; $P_{\mathrm{GiN}}$ and $P_{\mathrm{WN}}$ are the rated capacity of synchronous generator $i$ and DFIG-based wind turbine, respectively.

In the steady state, when the frequency variation of the whole system is $\Delta f$, the frequency regulation output of all generators in the system $\Delta P_{\Sigma}$ can be calculated as

$$
\Delta P_{\Sigma}=\sum_{i=1}^{n} \Delta P_{\mathrm{G} i}+\Delta P_{\mathrm{W}}
$$

From (8)-(10), we can obtain

$$
\Delta P_{\Sigma}=-\frac{\Delta f}{f_{\mathrm{N}}}\left(\sum_{i=1}^{n} \frac{P_{\mathrm{GiN}}}{R_{i *}}+\frac{P_{\mathrm{WN}}}{R_{\mathrm{W} *}}\right)
$$

If all generators involved in the system are replaced by an equivalent generator, the frequency regulation output of the system is

$$
\Delta P_{\Sigma}=-\frac{1}{R_{\Sigma *}} \frac{\Delta f}{f_{\mathrm{N}}} P_{\Sigma \mathrm{N}}
$$

where $R_{\Sigma *}$ is the equivalent adjustment coefficient and $P_{\Sigma \mathrm{N}}$ is the total capacity of the system. From (8) and (9), we can derive

$$
-\Delta f_{*}=\frac{R_{i *} \Delta P_{\mathrm{G} i}}{P_{\mathrm{GiN}}}=\frac{R_{\mathrm{W} *} \Delta P_{\mathrm{W}}}{P_{\mathrm{WN}}}=\frac{R_{\Sigma *} \Delta P_{\Sigma}}{P_{\Sigma \mathrm{N}}}
$$

Based on (11) and (12), one can further obtain

$$
R_{\Sigma *}=\frac{P_{\Sigma \mathrm{N}}}{\sum_{i=1}^{n}\left(P_{\mathrm{GiN}} / R_{i *}\right)+P_{\mathrm{WN}} / R_{\mathrm{W} *}}
$$

Equations (12) and (15) illustrate that, from the point of view of the whole power network, when the capacity connected to the system is a constant, the smaller adjustment coefficient of each parallel operation generator is, the smaller equivalent adjustment coefficient $R_{\Sigma *}$ of the system will be, and the larger unit power regulation is, the better ability of primary frequency regulation will be; on the contrary, the larger adjustment coefficient of each parallel operation generator is, the larger equivalent adjustment coefficient $R_{\Sigma *}$ of the system will be, and the smaller unit power regulation is, the weaker ability of primary frequency regulation will be. From (13), when the system load changes, the power of each generator can be determined as

$$
\Delta P_{i}=\frac{R_{\Sigma *} \Delta P_{\Sigma}}{P_{\Sigma \mathrm{N}}} \times \frac{P_{\mathrm{GiN}}}{R_{i *}}
$$

When the wind turbines that have no frequency regulation ability are connected to the power grid, $P_{\mathrm{WN}} / R_{\mathrm{W} *} \approx 0$, and $R_{\mathrm{W} *}$ goes to infinity. Then the remaining synchronous generators use differential control schemes. If more wind turbines with no frequency regulation ability replace traditional synchronous generators, which are connected to the power grid, then we know that $P_{\mathrm{WN}} / R_{\mathrm{W} *}=0$ and $R_{\Sigma *}$ of the system will become larger. Hence, connecting the large-scale wind turbines with no frequency regulation ability to the power network will obviously reduce the frequency regulation capability of the system. 


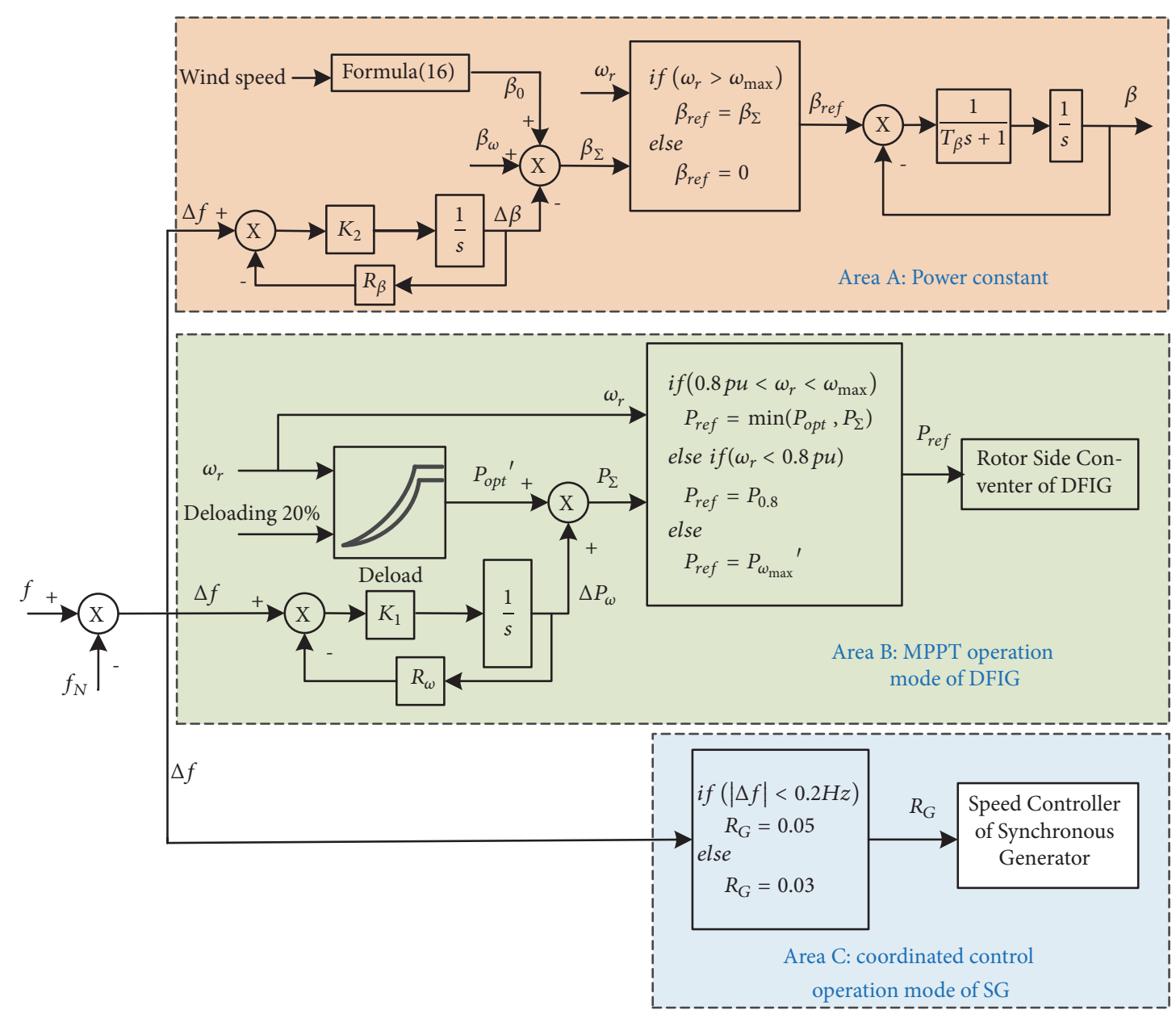

FIGURE 3: Primary coordinated frequency regulation structure of DFIG and synchronous generator.

\section{Coordinated Strategy for Frequency Regulation}

The primary frequency regulation control system coordinated by DFIGs and synchronous generators is shown in Figure 2. The overall system consists of three control modules: (1) area A: in this area, the power is constant; then through tuning the pitch angle action system, the active power output of DFIGs can be adjusted to adapt the change of the system frequency; (2) area B: this area is the maximum power point tracking module. It can realize the ability of power reservation by switching the running profile of the DFIG and adjusting the active power of the DFIG to participate in the frequency regulation according to the tuning variable adjustment coefficient; (3) area C: this area is the coordinated control module for the synchronous generator. According to the system frequency deviation, we choose the corresponding adjustment coefficient and coordinate the frequency regulation output between the synchronous generators and DFIGs.

4.1. Control Strategy of Primary Frequency Regulation with DFIG-Based Turbine. In this paper, the traditional operation mode of DFIG is modified and improved. In the maximum power point tracking area, the DFIG controls deloading operation through increasing or reducing the rotor speed. While in the constant power area, it can reserve the active power by adjusting the pitch angle, so that the DFIG has the frequency regulation capacity.

4.1.1. Maximum Power Point Tracking Control. Inspired by the principle of synchronous generator speed governor, a primary frequency regulation controller attached to the rotor side converter of a wind turbine is designed in this paper. We make the DFIG-based wind turbine whose load is reduced by $20 \%$ operate at the current wind speed, which is shown in area A in Figure 3. In this figure, $\omega_{\mathrm{r}}$ is the corresponding rotor speed at the current wind speed, $P_{o p t}^{\prime}$ is the suboptimal power when the wind turbine's load is reduced by $20 \%, R_{\omega}$ is the adjustment coefficient of the DFIG maximum power point tracking module, $f$ is the real-time frequency of the system, $f_{\mathrm{N}}$ is the rated frequency of the system, $K_{1}$ is the gain value, $\Delta P_{\omega}$ is the frequency regulation power of DFIGbased wind turbine corresponding to the system frequency variation, and $P_{\Sigma}$ is the sum of suboptimal power $P_{o p t}^{\prime}$ and frequency regulation power $\Delta P_{\omega}$. 
For the wind turbines, the frequency regulation power corresponding to the frequency variation is

$$
\Delta P_{\omega}=-\frac{\Delta f}{R_{\omega}}=\frac{\Delta f}{\Delta f_{0}} P_{0}
$$

DFIG-based wind turbines can participate in the frequency regulation as the traditional synchronous generators if the variable adjustment coefficient is tuned at the maximum power point tracking area, and the adjustment coefficient can be adjusted automatically according to the current wind speed to determine the amount of frequency regulation power.

4.1.2. Control Strategy in Power Constant Area. In this paper, we introduce the regulation coefficient of the pitch angle. Through improving the traditional pitch angle control system, the DFIG can also realize the function of deloading reservation in the power constant area to respond to the system frequency variation. In the constant power area, deloading operation of DFIG can be achieved by presetting the pitch angle $\beta_{0}$, which is calculated by the following equation:

$$
\begin{aligned}
(1- & d \%) 0.44 \sin \frac{\pi\left(\lambda_{c}-3\right)}{15} \\
= & \left(0.44-0.0167 \beta_{0}\right) \sin \frac{\pi\left(\lambda_{c}-3\right)}{15-0.3 \beta_{0}} \\
& -0.00184\left(\lambda_{c}-3\right) \beta_{0}
\end{aligned}
$$

where the tip speed ratio of DFIG-based wind turbine is defined as $\lambda_{c}=R_{\omega \max } / \nu$.

According to the principle of synchronous generator governor, we design the controller of pitch angle for area B as shown in Figure 3. In the figure, $\beta_{\omega}$ is the pitch angle of the DFIG-based wind turbine when the power is constant. $\Delta f$ is the difference between the system's current frequency $f$ and the rated frequency $f_{\mathrm{N}} \cdot R_{\beta}$ is the static adjustment coefficient of pitch angle. $K_{2}$ is the gain value. In the power constant area, the improved pitch angle control system enables DFIG to adapt to the current wind speed by adjusting the pitch angle according to its characteristic.

When the DFIG-based wind turbine is involved in the frequency regulation, the movement range of pitch angle is

$$
\Delta \beta=-\frac{\Delta f}{R_{\beta}}=\frac{\Delta f}{\Delta f_{0}} \beta_{0}
$$

In the constant power area, the variable adjustment coefficient between the pitch angle and the frequency characteristic is introduced and tuned. DFIG-based wind turbines can respond to the system frequency variation through changing mechanical power captured by the DFIG according to the variation of system frequency. Thus, DFIG is able to participate in the frequency adjustment process. between DFIG and Synchronous Generator. For the system with multiple generators, the frequency adjustment can be coordinated and achieved by those generators which have frequency regulation ability. When DFIG-based wind turbines are connected to the system, it is necessary for the traditional generators to detect the inclusion of these new generators. When the system frequency changes, part of the frequency regulation power will be allocated to the wind turbines according to the wind speed $[24,25]$ and the induced frequency deviation. Therefore, it is necessary to divide the frequency regulation region of the system according to the magnitude of the system frequency deviation.

The control and coordination strategies of the synchronous generators are shown in area $\mathrm{C}$ in Figure 2. The basic methods are summarized as follows.

(1) When the system is in the normal operation region and the frequency deviation is within the allowable range $(0.2 \mathrm{~Hz})$, if DFIG-based wind turbines are used in the frequency regulation and deloading operation, it will lead to a wind power curtailment and reduction of the wind power's economic efficiency. In general, the adjustment coefficient of SG is between 0.03 and 0.05 . In this case, in order to reduce the frequency regulation output of SGs, we set the regulation coefficient $R_{\mathrm{G}}$ to 0.05 , so that the more reserved power of DFIG-based wind turbines will be used for the frequency regulation and the "abandoned air" will be reduced. In particular, in the power constant area, the reserved power of DIFG-based wind turbines is larger, and thus the adjustable frequency power output will be increased as well.

(2) The frequency deviation is large when the system is in the emergency regulatory area. In order to make the system run stably and accelerate the recovery of system frequency, the synchronous generators and DFIG-based wind turbines should be used in the system frequency regulation as much as possible. The adjustment coefficient of the synchronous generator is usually set to 0.03 , so that the DFIGs participate in the system frequency regulation as much as possible according to the current wind speed.

The above-mentioned coordinate control strategies for the studied system with DFIGs and synchronous generator can be implemented by using the following steps:

(1) Measure the system frequency and calculate the frequency variations

(2) If the frequency variation is larger than $0.2 \mathrm{~Hz}$, we set the adjustment coefficient of the SG as 0.03; otherwise, we set the adjustment coefficient of the SG as 0.05

(3) Measure the rotor's speed $\omega_{\mathrm{r}}$ of the DIFG under the current wind speed

(4) If $\omega_{\mathrm{r}}>\omega_{\max }$, we can calculate the pitch adjusting coefficient $R_{\beta}$ in the constant area based on (17) and then apply the obtained $R_{\beta}$ to the pitch operation system

(5) If $\omega_{\mathrm{r}} \leq \omega_{\max }$, we can calculate the pitch adjusting coefficient $R_{\omega}$ in the maximum power tracking area based on (17) and then apply the obtained $R_{\omega}$ to the pitch operation system

(6) Calculate the primary frequency regulation of the synchronous generator, $\Delta P_{\mathrm{G}}$, based on the result of Step (2) and the primary frequency regulation of DFIG, $\Delta P_{\mathrm{W}}$, based on Step (4) or (5). Then we obtain the total frequency regulation of the system as $\Delta P_{\Sigma}=\Delta P_{\mathrm{G}}+\Delta P_{\mathrm{W}}$. 


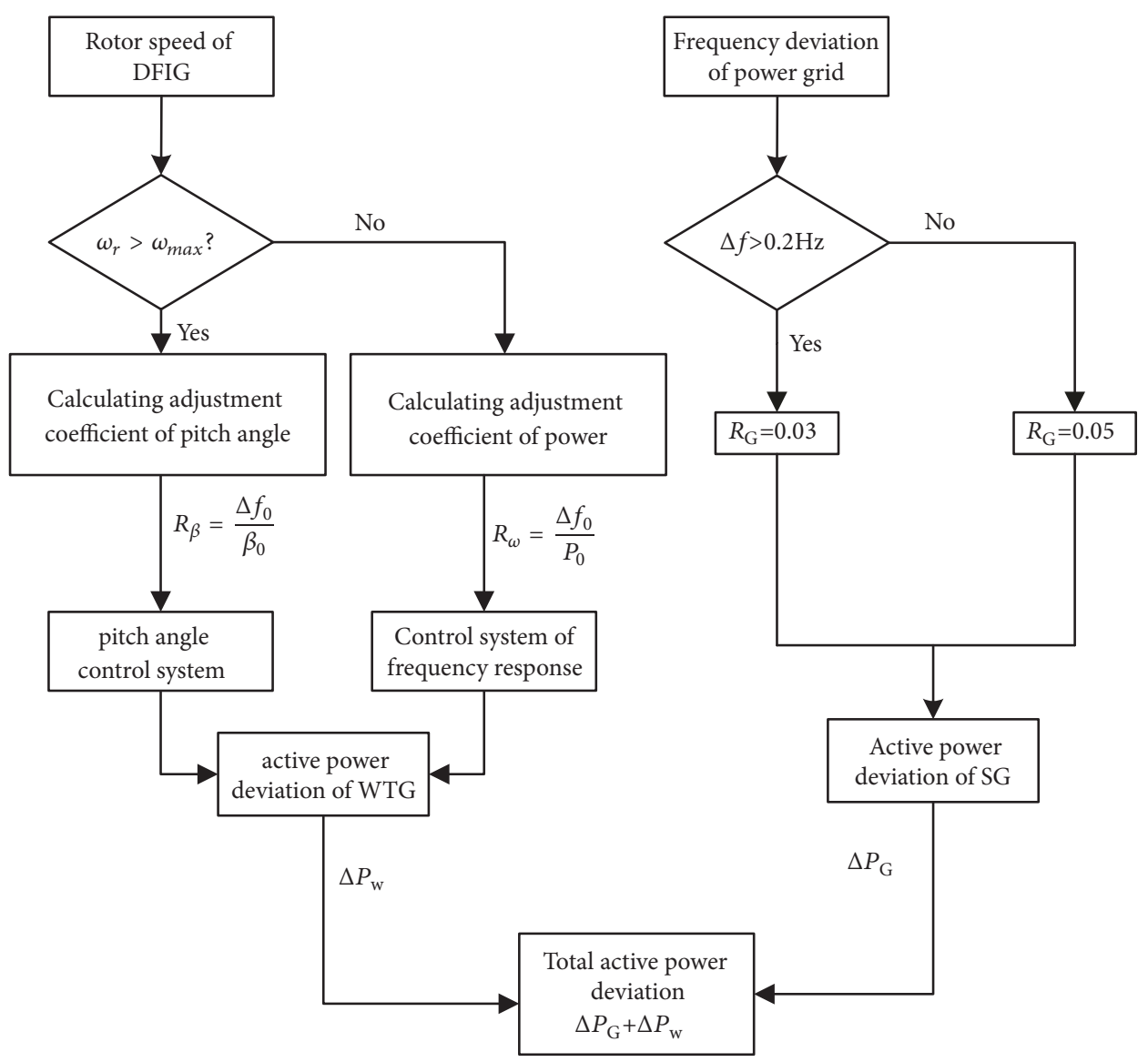

FIGURE 4: Flow chart of the proposed algorithm.

The practical implementation of the proposed algorithm can be found in Figure 4 .

\section{Simulations}

In order to verify the effectiveness of the proposed frequency regulation strategy, we use Matlab/Simulink to carry out simulations, where the simulated model includes 4-generator and 2-area power grid [26]. The structure of this test system is shown in Figure 5. The power grid model consists of 3 traditional synchronous generators with a rated power of $700 \mathrm{MW}$, and the inertial time constant is 6.5s. In addition, a DFIGbased wind turbine with equivalent capacity $800 \times 15 \mathrm{MW}$ is connected to bus 2; the upper limit of active power per unit is 1 , and the capacities of load L1 and L2 are $1200 \mathrm{MW}$ and $1800 \mathrm{MW}$, respectively. The variable pitch time constant of the wind turbine is $3 \mathrm{~s}$ and the rated wind speed is $12 \mathrm{~m} / \mathrm{s}$. In the model, the DFIG-based wind turbine is operated in the condition of reducing $20 \%$ load, and there is a load jump on L1 at the time of 40s. In practical situations, wind farm participating in frequency regulation is generally selected in rich wind area. Moreover, when the scale of wind farm is very large, the gathering effect of wind energy is also significant as it can decrease the fluctuation of wind speed and output power. Accordingly, the wind speed becomes flatter.
In this paper, the major focus is on the feasibility analysis of participation of wind turbine in frequency regulation; hence, we select a constant wind speed in the simulation. In this simulation, the output active power of DFIG and SG is per unite value based on $S_{\mathrm{B}}$.

5.1. Load Variation in Maximum Power Point Tracking Area. Two cases are simulated in this study: (a) the frequency variation is less than $0.2 \mathrm{~Hz}$ and (b) the frequency variation is larger than $0.2 \mathrm{~Hz}$.

In case (a), the wind speed is set to $9 \mathrm{~m} / \mathrm{s}$. At the time of 40 s, the applied load suddenly increases by $300 \mathrm{MW}$, and then the frequency has a deviation less than $0.2 \mathrm{~Hz}$. The adjustment coefficients of the SG, $R_{\mathrm{G}}$, are set to $0.03,0.04$, and 0.05 , respectively. The corresponding simulation results are shown in Figure 6.

In Figure 6, we find that the frequency regulation output of the SG is gradually reduced as long as the adjustment coefficient increases (Figure 6(b)), while the frequency regulation output of the DFIG-based wind turbine is gradually increased (Figure 6(c)). From the point of view of the system frequency recovery, the frequency recovery response is the best when we set $R_{\mathrm{G}}=0.03$ as shown in Figure 6(a). However, if the adjustment coefficient of the SG is small, the frequency regulation output of DFIG is limited as shown in Figure 6(c). 


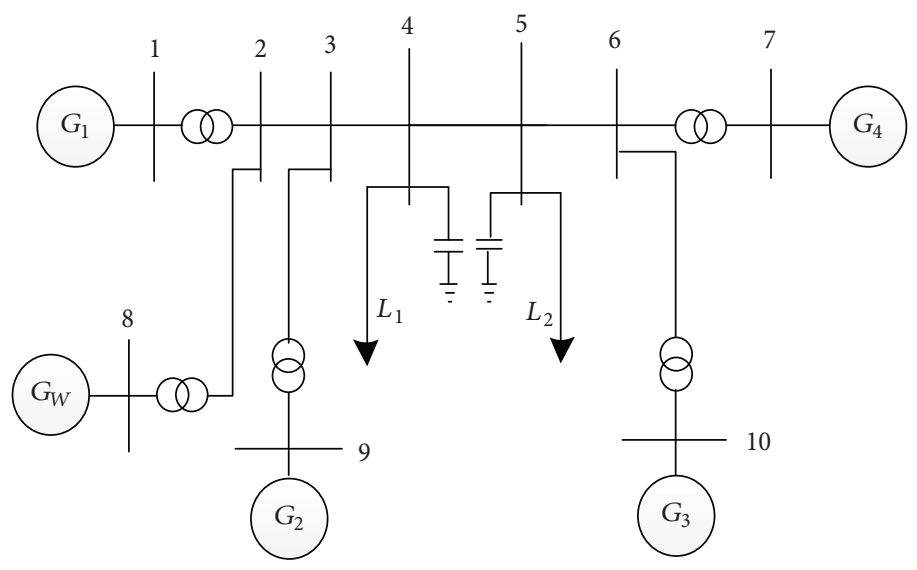

FIGURE 5: The structure of 2-area test system.

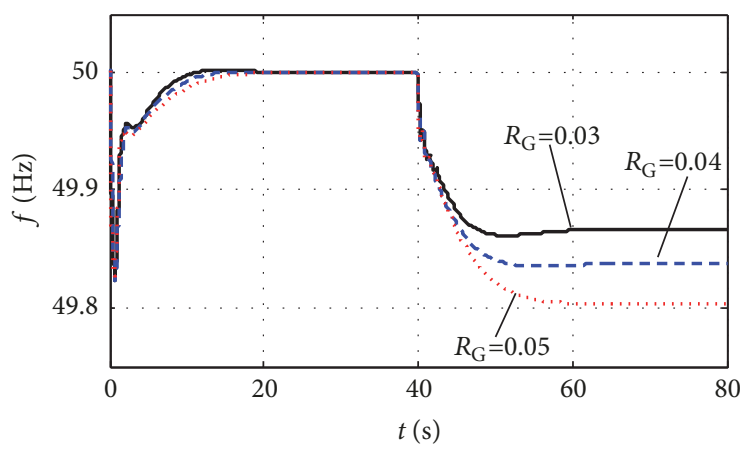

(a) Frequency variation

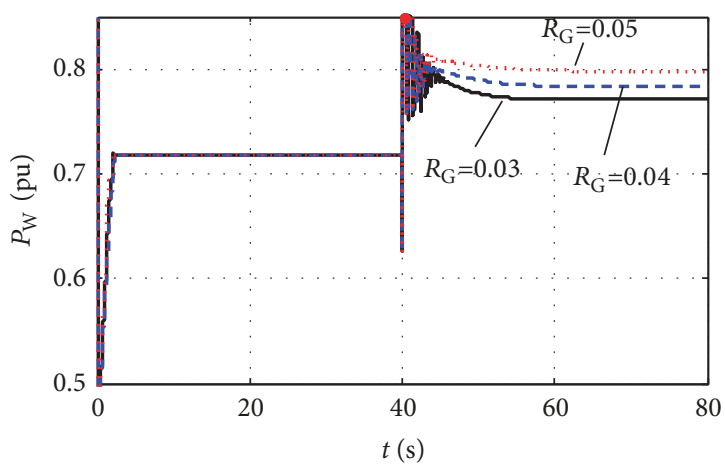

(c) Output of DFIG-based wind turbine

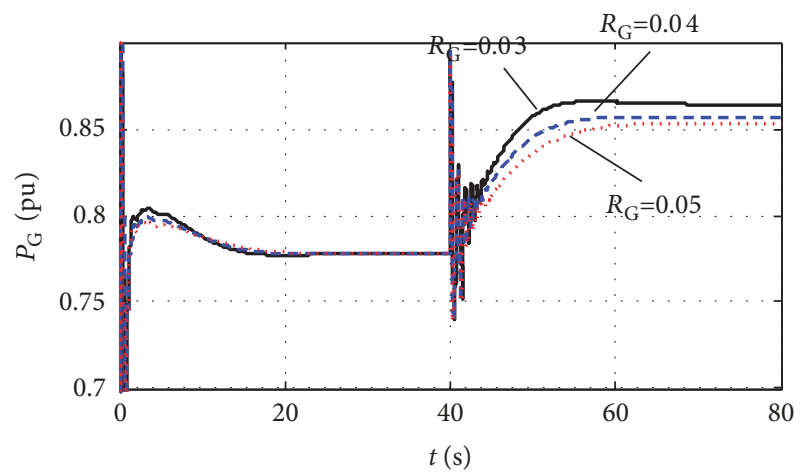

(b) Output of synchronous generators

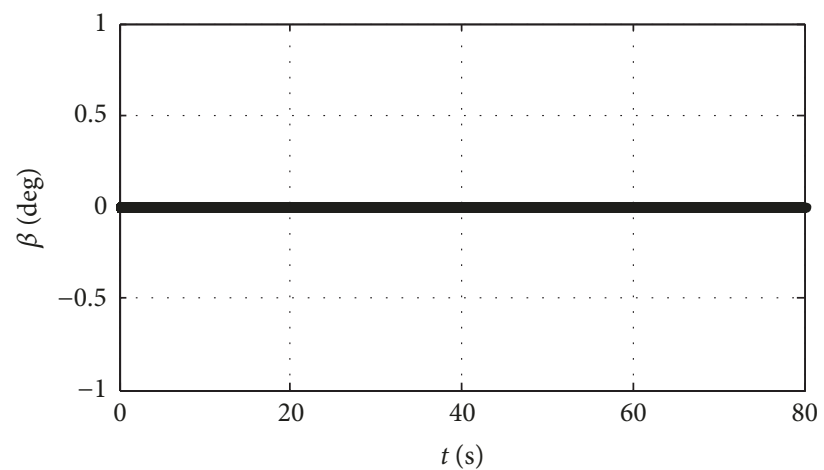

(d) Pitch angle variation

FIGURE 6: Simulation results of the maximum power tracking area when frequency change is less than $0.2 \mathrm{~Hz}$.

When we set $R_{\mathrm{G}}=0.05$, the frequency can also be retained within a bound around $0.2 \mathrm{~Hz}$, and the system frequency is relatively stable. Therefore, in order to increase the frequency regulation output of the DFIG-based wind turbines as much as possible and make full use of the restored power of the DFIG-based wind turbine for frequency regulation, we can take $R_{\mathrm{G}}=0.05$. The pitch angle variation is also shown in Figure 6(d). The fluctuations shown in Figure 6 are due to the fact that the system is operated in the MTTP area and the frequency variation is larger than $0.2 \mathrm{~Hz}$, so that it will take some transient periods to achieve a new steady state because of the limited control effect of $\Delta f$.

In case (b), the wind speed is also $9 \mathrm{~m} / \mathrm{s}$. At the time of 40 s, the applied load suddenly increases by $600 \mathrm{MW}$; the frequency has a deviation larger than $0.2 \mathrm{~Hz}$. The adjustment coefficients of the synchronous generator are also the same as (a). The corresponding simulation results are shown in Figure 7. According to Figure 7(a), the frequency recovery response is the best when we set $R_{\mathrm{G}}=0.03$. When the frequency change is greater than $0.2 \mathrm{~Hz}$, the system is in the 


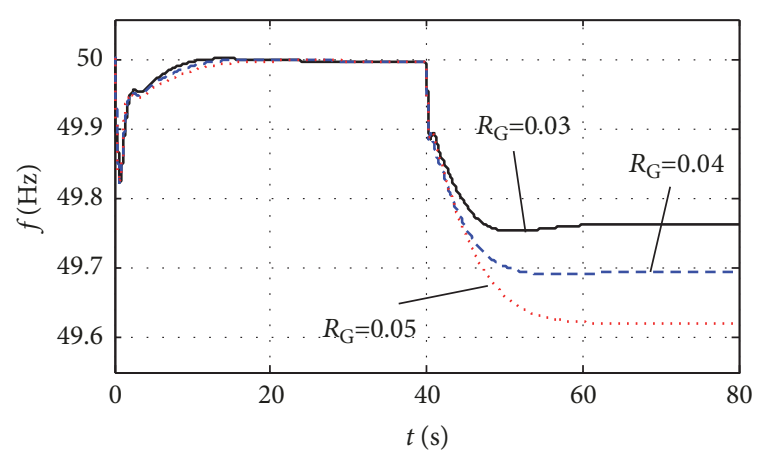

(a) Frequency variation

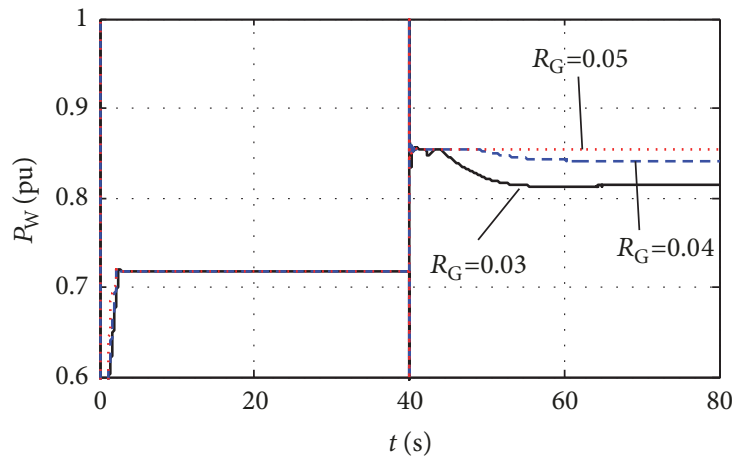

(c) Output of DFIG-based wind turbine

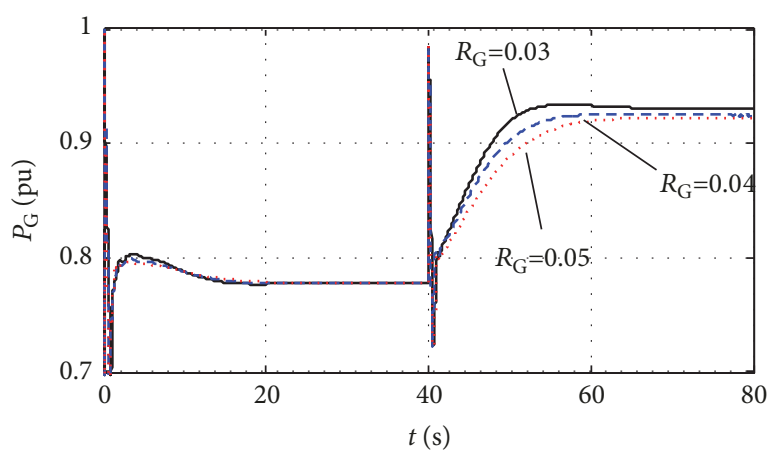

(b) Output of synchronous generators

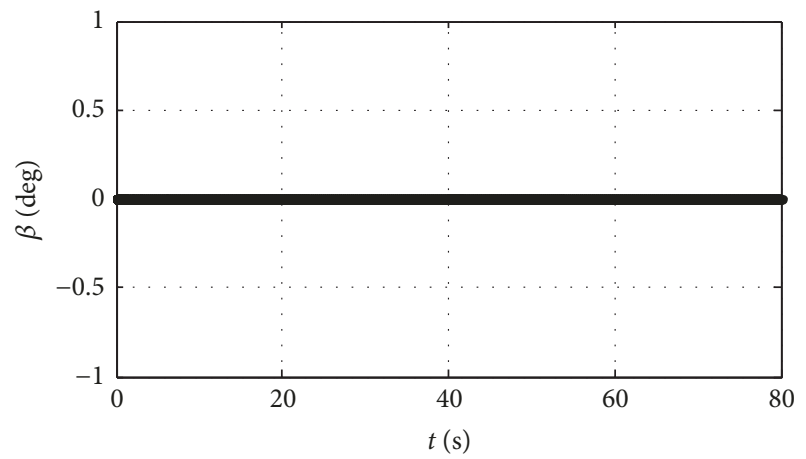

(d) Pitch angle variation

FIGURE 7: Simulation curves of the maximum power tracking area when frequency change is greater than $0.2 \mathrm{~Hz}$.

emergency frequency modulation stage, and the ultimate goal is to improve the frequency recovery effect of the system. All synchronous generators and DFIGs should output power as much as possible, which are shown in Figures 7(b) and 7(c). According to the frequency recovery effect of Figure $7(a)$ and the pitch angle variation shown in Figure 7(d), the adjustment coefficient of the synchronous machine should be set as $R_{\mathrm{G}}=0.03$.

5.2. Load Variation in Constant Power Area. Two cases at the constant power areas are simulated in this study: (a) the frequency variation is larger than $0.2 \mathrm{~Hz}$, and (b) the frequency variation is less than $0.2 \mathrm{~Hz}$.

In case (a), in the constant power area, the wind energy captured by DFIG is mainly regulated by adjusting the pitch angle controlled by the pitch control mechanism. The wind speed is set as $15 \mathrm{~m} / \mathrm{s}$. At the time of 40 s, the load suddenly increases by $600 \mathrm{MW}$; then the frequency has a deviation more than $0.2 \mathrm{~Hz}$. The adjustment coefficients of SG, $R_{\mathrm{G}}$, are set as $0.03,0.04$, and 0.05 respectively. The simulation results are shown in Figure 8.

In Figure 8 , when $R_{\mathrm{G}}$ is set as 0.03 , the frequency recovery performance is the best among these three cases and the frequency deviation can be retained within a bound $0.02 \mathrm{~Hz}$ as shown in Figure 8(a). Because the frequency deviation is more than $0.2 \mathrm{~Hz}$ at one period during the process of frequency recovery, the magnitude of the frequency deviation is larger than the normal value. Thus, the system enters in the emergency control phase. In order to make the system frequency recover better, the DFIG-based wind turbine can make full use of the restored power for frequency regulation when the power is constant, the wind speed is fast, and the DFIG has much reserved power. From the frequency recovery result in Figure 8(a), when we take $R_{\mathrm{G}}=0.03$, the DFIG-based wind turbine and synchronous generators can participate in the frequency regulation as much as possible (Figure 8(b)). Figure 8(c) also shows that the output of DFIG wind turbines has reached the upper limit of active power per unit. Thus, we can put $20 \%$ of the reserved power into the frequency regulation as a part of the frequency regulation power, such that the minimum value of the frequency drop and the steadystate deviation responses have been significantly improved. Figure $8(\mathrm{~d})$ provides the corresponding pitch angle variation.

In case (b), the wind speed is set as $15 \mathrm{~m} / \mathrm{s}$. At the time of 40 s, the load suddenly increases by $300 \mathrm{MW}$; the frequency has a deviation less than $0.2 \mathrm{~Hz}$. The adjustment coefficients of SG, $R_{\mathrm{G}}$, are set to $0.03,0.04$, and 0.05 , respectively. The simulation results are shown in Figure 9. When the system frequency is reduced within $0.2 \mathrm{~Hz}$, the frequency can be restored well when $R_{\mathrm{G}}=0.03,0.04$, and 0.05 according to the frequency variation in Figure 9(a). Figure 9(d) shows that when $R_{\mathrm{G}}=0.05$, the action range of pitch angle is the largest, reaching $2.8^{\circ}$, and the reserve power of DFIG released amounts to $0.07 \mathrm{pu}$ (Figure 9(b)), which reduces the steadystate frequency deviation of the system to $0.15 \mathrm{~Hz}$. This shows that the DFIG effectively reduces the power change rate of 


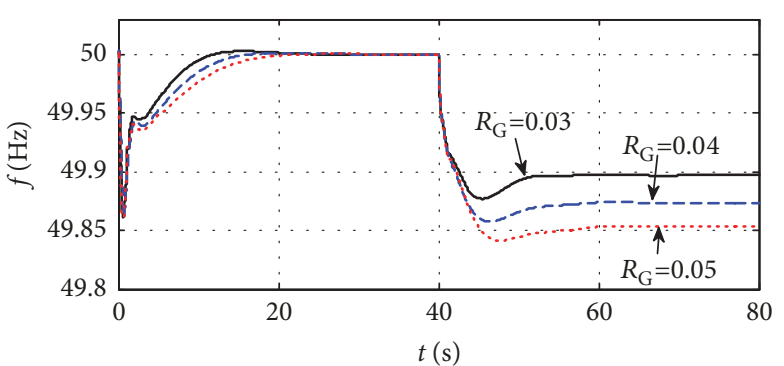

(a) Output of synchronous generators

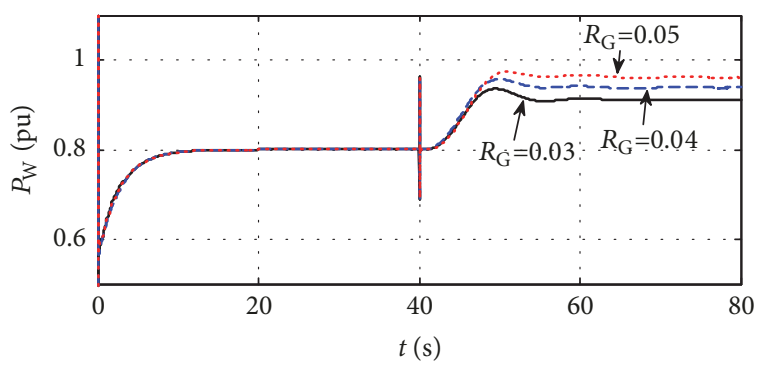

(c) Output of synchronous generators

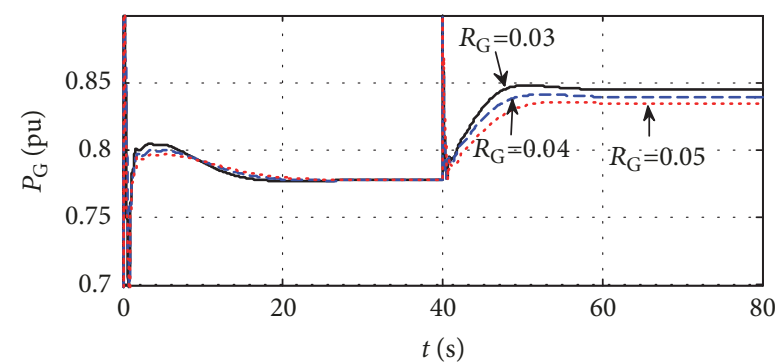

(b) Output of synchronous generators

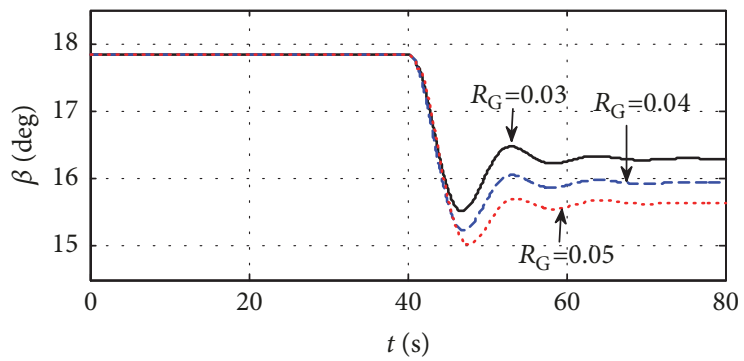

(d) Pitch angle variation

FIGURE 8: Simulation diagram of the power constant area when frequency variation is greater than $0.2 \mathrm{~Hz}$.

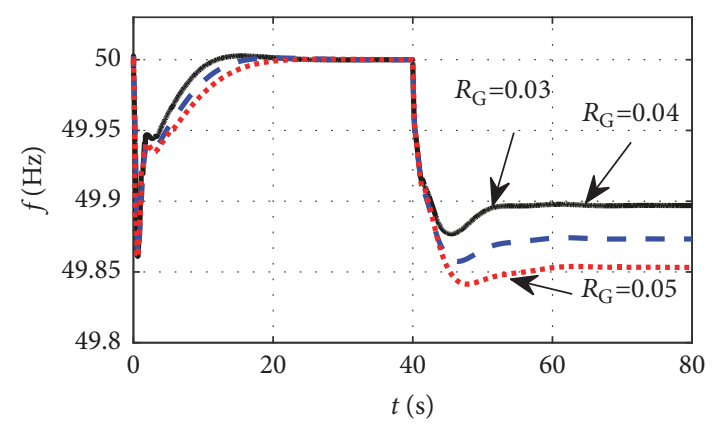

(a) Frequency variation

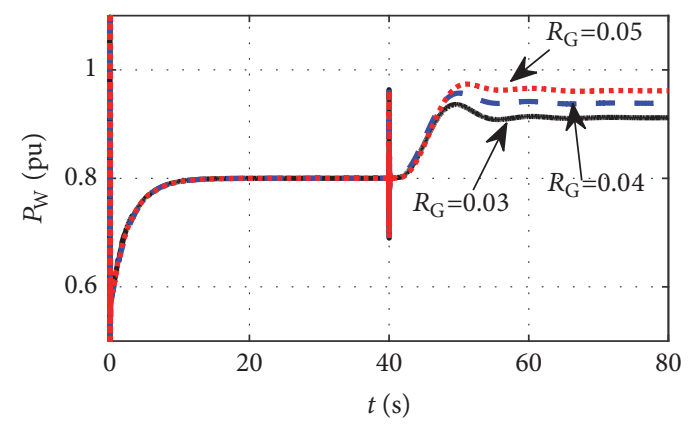

(c) Output of DFIG-based wind turbine

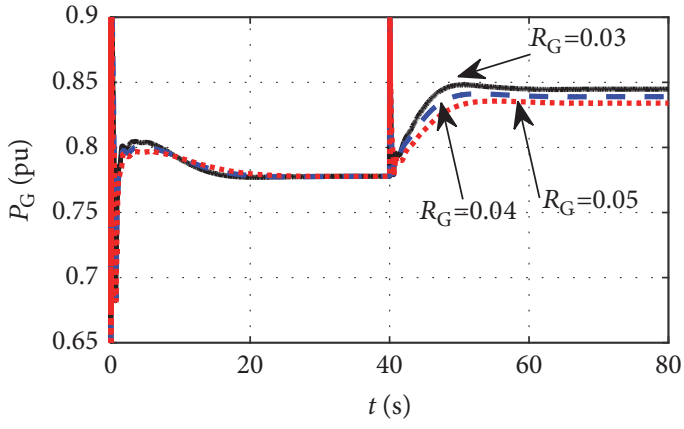

(b) Output of synchronous generators

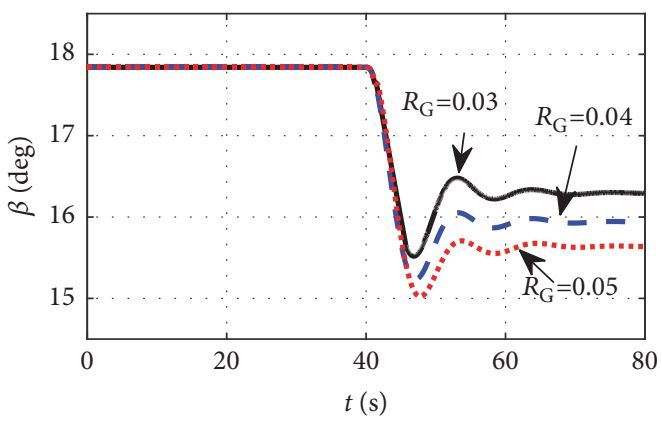

(d) Pitch angle variation

FIgURE 9: Simulation diagram of the power constant area when frequency variation is less than $0.2 \mathrm{~Hz}$.

SG in the initial stage of frequency change (Figure 9(c)) and can continuously provide active power effective support for power grid.

In the process of frequency modulation, the reserve power of DFIG can be fully used for frequency regulation by increasing the power output of DFIG, thus indirectly reducing the wind abandonment. The simulation results of Figure 9 show that when the frequency varies within the allowable range, the larger the $R_{\mathrm{G}}$ value is, the smaller the static adjustment coefficient $R_{\beta}$ of pitch angle will be. The range of pitch angle action will be larger, and the frequency regulation capability of DFIG will be enhanced, so that it can 
undertake more power output and further reduce the steadystate frequency deviation of power grid.

\section{Conclusions}

In this paper, we presented a control strategy for system with the wind turbines being incorporated into the frequency regulation by further tailoring the primary frequency regulation principle of traditional synchronous generators. The DFIG can provide inertial power support to the power grid and participate in the frequency regulation together with the synchronous generators. Through theoretical analysis and simulation verifications, the following conclusions can be obtained:

(1) The wind turbines with adjustable frequency can effectively undertake the frequency regulation responsibility of the power grid, and the frequency regulation output between the synchronous generators and the DFIG-based wind turbines can be coordinated and allocated by adjusting $R_{\mathrm{G} *}$ and $R_{\mathrm{W} *}$.

(2) The variable difference coefficient of DFIG in different wind speed sections is defined and calibrated. In corresponding to the wind speed changes in real time, the frequency regulation output can be determined considering the current reserved capacity.

(3) Through coordinating the frequency regulation output between the DFIG and the synchronous generators, the frequency deviation is retained within the allowable ranges, and the resorted power of the DFIG-based wind turbine can be used for the frequency regulation as much as possible. Those proposed methods can not only meet the demand of the power network frequency regulation but also minimize the "abandoned air" generated by the DIFG load reduction.

Future work will focus on validating the proposed coordinate and control strategies under more realistic wind speed and operation scenarios.

\section{Data Availability}

The data used to support the findings of this study are available from the corresponding author upon request.

\section{Conflicts of Interest}

The authors declare that there are no conflicts of interest regarding the publication of this paper.

\section{Acknowledgments}

This research was supported in part by the Yunnan Electrical Power Experiment Institute.

\section{References}

[1] J. Dong, G. Xue, M. Dong, and X. Xu, "Energy-saving power generation dispatching in China: Regulations, pilot projects and policy recommendations - A review," Renewable \& Sustainable Energy Reviews, vol. 43, pp. 1285-1300, 2015.
[2] R. Saidur, N. A. Rahim, M. R. Islam, and K. H. Solangi, "Environmental impact of wind energy," Renewable \& Sustainable Energy Reviews, vol. 15, no. 5, pp. 2423-2430, 2011.

[3] G. Lalor, A. Mullane, and M. O’Malley, "Frequency control and wind turbine technologies," IEEE Transactions on Power Systems, vol. 20, no. 4, pp. 1905-1913, 2005.

[4] J. Ekanayake and N. Jenkins, "Comparison of the response of doubly fed and fixed-speed induction generator wind turbines to changes in network frequency," IEEE Transactions on Energy Conversion, vol. 19, no. 4, pp. 800-802, 2004.

[5] H. Bevrani, A. Ghosh, and G. Ledwich, "Renewable energy sources and frequency regulation: Survey and new perspectives," IET Renewable Power Generation, vol. 4, no. 5, pp. 438457, 2010.

[6] R. G. de Almeida and J. A. Peças Lopes, "Participation of doubly fed induction wind generators in system frequency regulation," IEEE Transactions on Power Systems, vol. 22, no. 3, pp. 944-950, 2007.

[7] J. E. Sierra and M. Santos, "Wind and payload disturbance rejection control based on adaptive neural estimators: application on quadrotors," Complexity, vol. 2019, Article ID 6460156, 20 pages, 2019.

[8] Q. Guo, Z. Sun, Y. Zhang, and W. Xu, "Time-delayed feedback control in the multiple attractors wind-induced vibration energy harvesting system," Complexity, vol. 2019, Article ID 7973823, 11 pages, 2019.

[9] N. Nguyen and J. Mitra, "An analysis of the effects and dependency of wind power penetration on system frequency regulation," IEEE Transactions on Sustainable Energy, vol. 7, no. 1, pp. 354-363, 2016.

[10] J. C. G. Arispe and H. J. Florero, "Wind farms integration in power system and frequency regulation effects," IEEE Latin America Transactions, vol. 15, no. 4, pp. 698-704, 2017.

[11] N. Nguyen and J. Mitra, "An analysis of the effects and dependency of wind power penetration on system frequency regulation," in Proceedings of the 2016 IEEE Power and Energy Society General Meeting (PESGM), pp. 1-1, Boston, Mass, USA, July 2016.

[12] X. Tian, W. Wang, L. Yan et al., "Coordinative control strategy of virtual inertia and primary frequency of DFIGs based wind farms," in Proceedings of the 2016 IEEE PES Asia Pacific Power and Energy Engineering Conference, APPEEC 2016, pp. 21692174, Xi'an, China, October 2016.

[13] Z. Zhang, Y. Wang, H. Li, and X. Su, "Comparison of inertia control methods for DFIG-based wind turbines," in Proceedings of the 2013 IEEE ECCE Asia Downunder - 5th IEEE Annual International Energy Conversion Congress and Exhibition, IEEE ECCE Asia 2013, pp. 960-964, VIC, Melbourne, Australia, 2013.

[14] A. H. M. I. Ferdous, M. R. I. Sheikh, and M. A. Shobug, "Controlling of frequency fluctuation of wind turbine generator using wind speed controlled pitch controller," in Proceedings of the 2nd International Conference on Electrical, Computer and Telecommunication Engineering, ICECTE 2016, pp. 1-4, Rajshahi, Bangladesh, 2016.

[15] S. Hu and G. Zhu, "A vector control strategy of grid-connected brushless doubly fed induction generator based on the vector control of doubly fed induction generator," in Proceedings of the 31st Annual IEEE Applied Power Electronics Conference and Exposition, APEC 2016, pp. 3310-3316, Long Beach, Calif, USA, March 2016.

[16] J. Zhao, X. Lü, Y. Fu, and X. Hu, "Dynamic frequency control strategy of wind/photovoltaic/diesel microgrid based on DFIG 
virtual inertia control and pitch angle control," Proceedings of the Chinese Society of Electrical Engineering, vol. 35, no. 15, pp. 3815-3822, 2015.

[17] J. Zhao, X. Lyu, Y. Fu, X. Hu, and F. Li, "Coordinated microgrid frequency regulation based on dfig variable coefficient using virtual inertia and primary frequency control," IEEE Transactions on Energy Conversion, vol. 31, no. 3, pp. 833-845, 2016.

[18] A. Žertek, G. Verbič, and M. Pantoš, "A novel strategy for variable-speed wind turbines' participation in primary frequency control," IEEE Transactions on Sustainable Energy, vol. 3, no. 4, pp. 791-799, 2012.

[19] K. V. Vidyanandan and N. Senroy, "Primary frequency regulation by deloaded wind turbines using variable droop," IEEE Transactions on Power Systems, vol. 28, no. 2, pp. 837-846, 2013.

[20] J. Van De Vyver, J. D. M. De Kooning, B. Meersman, L. Vandevelde, and T. L. Vandoorn, "Droop control as an alternative inertial response strategy for the synthetic inertia on wind turbines," IEEE Transactions on Power Systems, vol. 31, no. 2, pp. 1129-1138, 2016.

[21] S. Ghosh, S. Kamalasadan, N. Senroy, and J. Enslin, "Doubly fed induction generator (DFIG)-based wind farm control framework for primary frequency and inertial response application," IEEE Transactions on Power Systems, vol. 31, no. 6, pp. 1861-1871, 2016.

[22] C. Wei, Z. Zhang, W. Qiao, and L. Qu, "Reinforcementlearning-based intelligent maximum power point tracking control for wind energy conversion systems," IEEE Transactions on Industrial Electronics, vol. 62, no. 10, pp. 6360-6370, 2015.

[23] C. Wei, Z. Zhang, W. Qiao, and L. Qu, "An adaptive networkbased reinforcement learning method for MPPT control of PMSG wind energy conversion systems," IEEE Transactions on Power Electronics, vol. 31, no. 11, pp. 7837-7848, 2016.

[24] I. Marović, I. Sušanj, and N. Ožanić, "Development of ANN model for wind speed prediction as a support for early warning system," Complexity, vol. 2017, Article ID 3418145, 10 pages, 2017.

[25] F. Cheng, L. Qu, W. Qiao, C. Wei, and L. Hao, "Fault diagnosis of wind turbine gearboxes based on DFIG stator current envelope analysis," IEEE Transactions on Sustainable Energy, Article ID 2859764, pp. 1-9, 2018.

[26] P. Kundur, N. J. Balu, and M. G. Lauby, Power System Stability and Control, McGraw-hill, New York, NY, USA, 1994. 


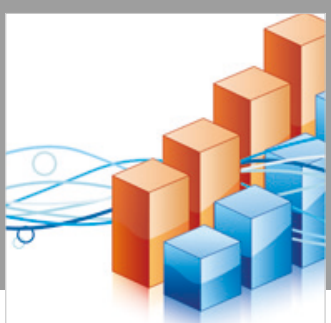

Advances in

Operations Research

\section{-n-m}
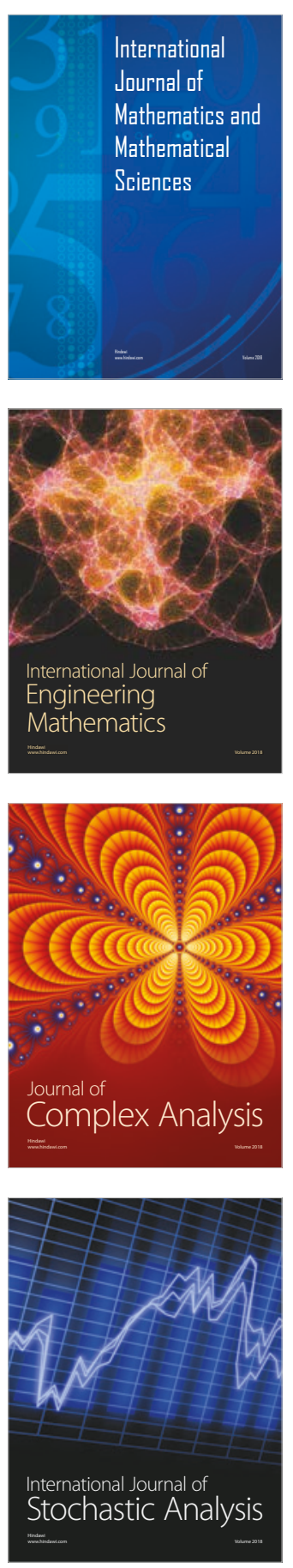
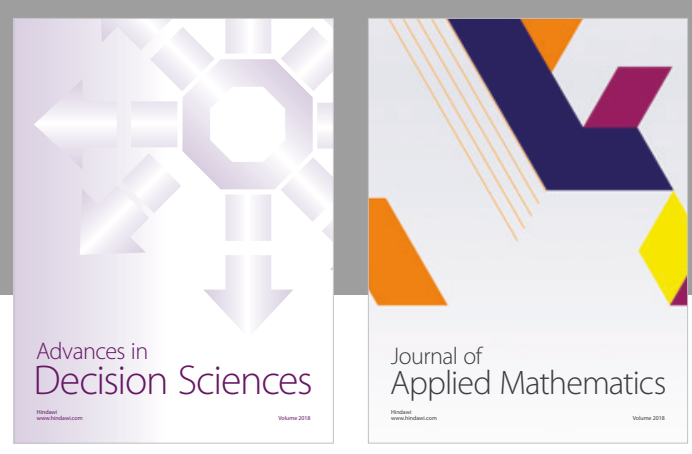

Journal of

Applied Mathematics
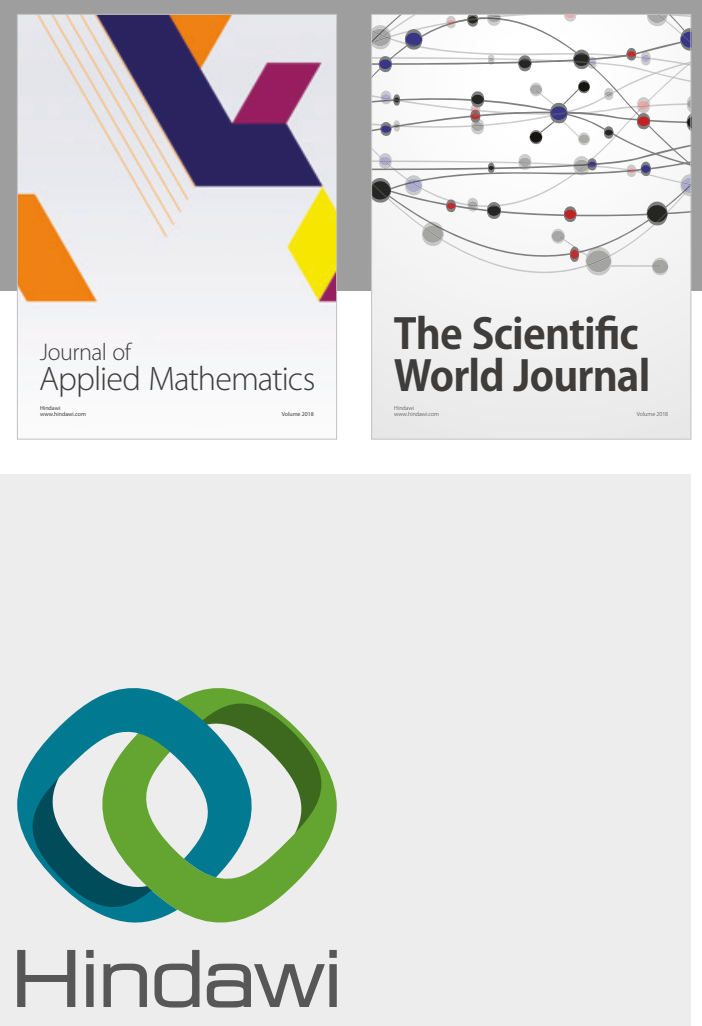

Submit your manuscripts at

www.hindawi.com

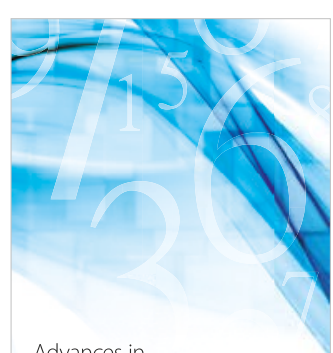

Advances in
Numerical Analysis
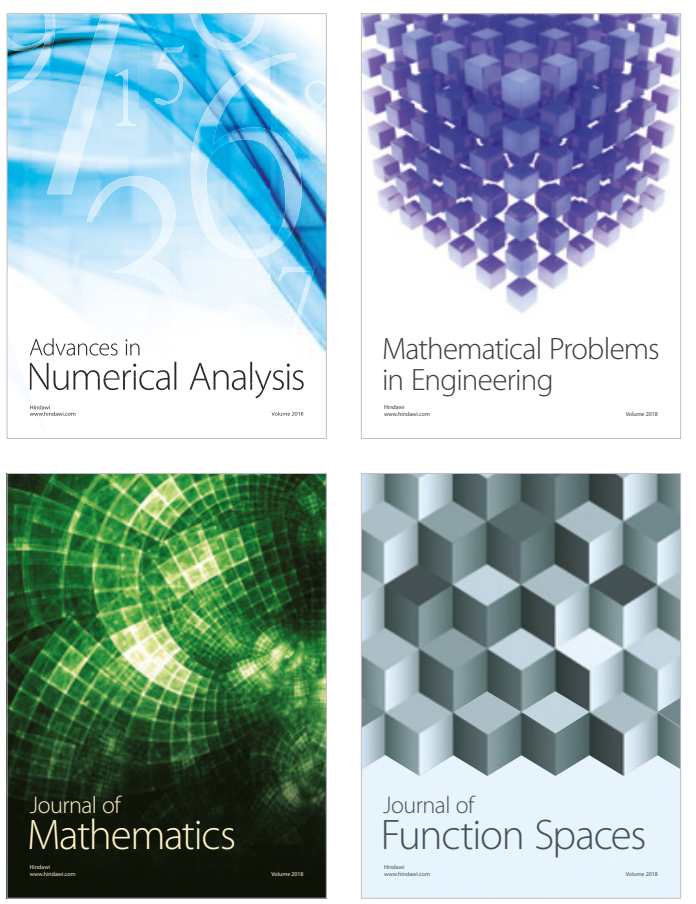

Mathematical Problems in Engineering

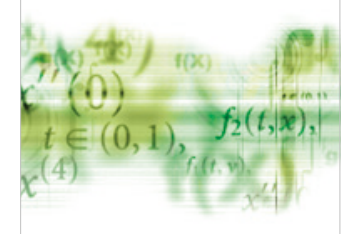

International Journal of

Differential Equations

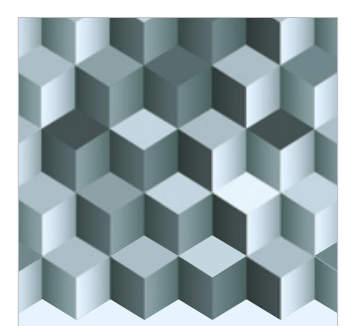

Journal of

Function Spaces
The Scientific

World Journal

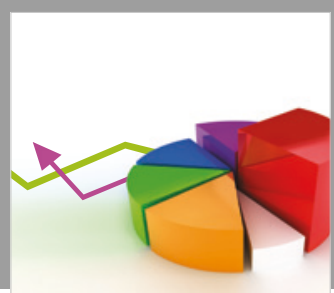

Journal of

Probability and Statistics
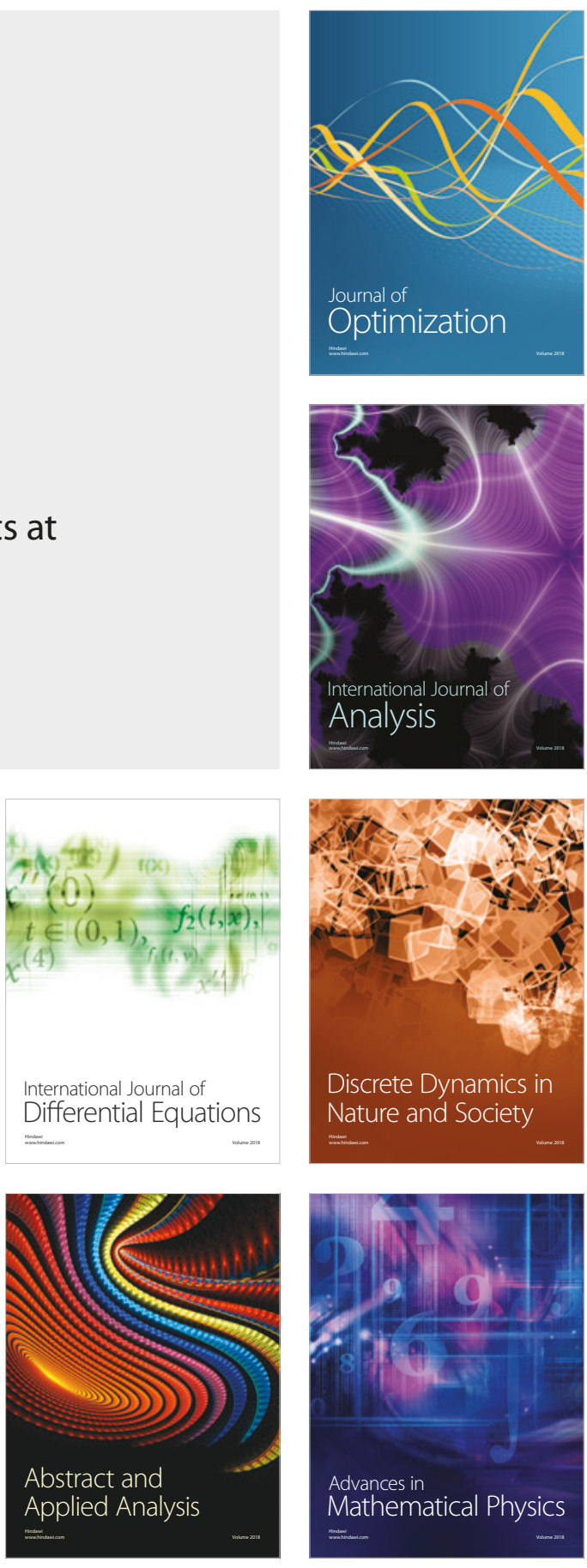